\title{
Investigation of Japanese electricity industry using a CGE model of translog function
}

\author{
Kwang II Kim * (]
}

${ }^{*}$ Correspondence:

platinumkwangil@gmail.com Graduate School

of Economics, Nagoya

University, Furo-cho,

Chikusa-ku, Nagoya-shi, Aichi

464-8601, Japan

\begin{abstract}
CGE models are usually used for policy analysis. The conventional CGE models use CES function because of being a convenience for modeling. Moreover, some of the CGE models use a multi-CES function to model the multi-layered production process. These multi-layered CES functions are frequently used in the energy and environmental policy analysis. However, the CES function is rigid for considering various substitution-complement relationships. In this regard, this study suggests another type of CGE model that uses the translog function for modeling of power generation. Taking the model into practice, we analyze the effects of the carbon tax on power generation in substitution and complement scenarios, as an application. We compare three carbon tax scenarios (289 Yen as BAU, 600 Yen, and $2000 \mathrm{Yen} / \mathrm{CO}_{2}$ ton) to investigate the impact of carbon tax on power generation. The results of the simulation show that industrial production decreases and substitution of the power sources for thermal power generation being significant in response to a carbon tax increase. Moreover, the result suggests that the translog function model is available for analysis of electricity industry under environmental policies.
\end{abstract}

Keywords: Computable general equilibrium, Translog function, Electricity industry, Substitution, Complement

\section{Introduction}

Recently, the share of renewable energy, e.g., photovoltaic, is increasing in power generation. Restriction of nuclear power generation in many countries in the world, which is triggered by Fukushima Daiichi accident in 2011, activated the discussion to supply massive power with renewable energy because it has low carbon emission and low risk. However, technological and economic restrictions are a barrier to making the electricity system with highly penetrated renewable energy. For example, in Japan, Kyushu Electric Power Company (KEPC) restricted connecting renewable energy power plants into its network to prevent blackouts (The Mainichi Newspaper 2018). KEPC's restriction shows that the massive installation of renewable energy makes the grid unstable. KEPC's restriction for renewable energy implies that the design of an ideal power supply system requires some challenges. In this context, the power supply is conducted by elaborately controlled energy mix.

Many literatures concerning energy policy use CGE analysis (e.g., Wissema and Dellink 2007; Aydin and Acar 2010; He et al. 2010; Danno et al. 2013; Guo et al. 2014; 
Hwang and Lee 2015; Benavente 2016; Peters 2016a, b; Yun et al. 2016; Tang et al. 2017; $\mathrm{Li}$ and Su 2017; Zhang et al. 2017). Generally, the CGE model has been using CES function, since the CES function is easy to use to make an economic model. Specifically, CES function easily describes substitutes relationship among the inputs or commodities. However, the CES function is not flexible enough to make a more realistic model. In the situation where renewable energy is primarily installed in a power generation system, volatility of renewable energy can generate an additional cost of grid stabilization. In the economic perspective, as KEPC's example implies, the additional cost of grid stabilization makes a difference between $1 \mathrm{kWh}$ from thermal or nuclear and $1 \mathrm{kWh}$ from renewable energy. CES function model hardly addresses this delicate situation, because of its rigidity. Our approach relaxes the strict assumption on the substitution pattern imposed by the CES function which can be adapted to the grid analysis.

In this context, the purpose of this work is to develop a CGE model based on the trans$\log$ function to investigate the issue of the energy mix in the power supply system. Moreover, as an application of the suggested model, we investigate the effects of the carbon tax on the electricity industry. Barbe (2014), referring Wilcoxen (1988) and Jorgenson and Yun (2001), introduced the CGE model that model the production using multilayered translog cost function. This study focuses on the power supply which is merely concerned by Barbe (2014) and analyzes the effect of carbon tax on Japanese power generation in substitution-complement scenarios. Although the results are not the final answer to energy policy design concerning power supply or grid stabilization, this paper contributes to the literature as a useful framework of the further related researches.

This article consists of five sections. First, we show the CGE model in Sect. 2. The CGE model is based on the Waseda university's expanded input-output table designed from Japanese input-output table in 2005. The Waseda university's input-output table segmented power generation industry. Moreover, the entire framework of my CGE model is based on Danno et al. (2013). The estimated parameters of the model are shown in Sect. 3. In Sect. 4, we present the simulated results and discuss the results. Finally, Sect. 5 draws some conclusions about the meaning of the results and the contribution of the paper and discusses remained challenges.

\section{Method}

\subsection{Data preparation}

The extended input-output table for analysis of next-generation energy system complied Waseda university is used. ${ }^{1}$ This study aggregates the 124 sectors of the original table into 16 sectors. Moreover, the original table segments electricity industry into eight sectors including transmission sector, we aggregated these into five sectors, these are the transmission, nuclear, thermal, hydro, and renewable energy. These five sectors are subsectors of the electricity industry (Table 1).

The social accounting matrix (SAM) created for the simulation is based on the mentioned Waseda university's input-output table. Note that some elements in the SAM are adjusted before simulation. While each power generation sector directly supplies

\footnotetext{
${ }^{1}$ Extended renewable energy sectors for 2005, Institute for Economic Analysis of Next-generation Science and Technology, Waseda University http://www.f.waseda.jp/washizu/table.html.
} 
Table 1 Industrial sectors

\begin{tabular}{lll}
\hline Sector No. & Description & Waseda Code \\
\hline S01 & Agriculture, forestry, livestock, fishing & $001000 \sim 005000$ \\
S02 & Fossil fuel & 008000 \\
S03 & Mining, ceramic, metal, non-metal, glass & $006000 \sim 007000,033000 \sim 044000$ \\
S04 & Other manufacturing & $009000 \sim 019000,032000,063000 \sim 064000$ \\
S05 & Chemical industry & $020000 \sim 031000$ \\
S06 & Mechanical, vehicle manufacturing & $045000 \sim 047000,057000 \sim 062000$ \\
S07 & Electrical manufacturing & $048000 \sim 056000$ \\
S08 & Construction & $065000 \sim 068400$ \\
S09 & Transportation & $078000 \sim 085000$ \\
S10 & Gas, heat, water, waste & $070100 \sim 072500$ \\
S11 & Other services & $073000 \sim 077000,086000 \sim 108000$ \\
S12-1 & Transmission & 069300 \\
S12-2 & Power generation (nuclear) & 069110 \\
S12-3 & Power generation (thermal) & 069120,069400 \\
S12-4 & Power generation (hydro) & 069130 \\
S12-5 & Power generation (renewable energy) & $069211 \sim 069241$ \\
\hline
\end{tabular}

electricity to industries and final demands in the original input-output table, we assume that only the transmission subsector supplies electricity because it is more realistic. Therefore, electricity from the four power generation subsectors is aggregated into the transmission subsector. Inversely, the transmission subsector is assumed that it does not produce value-added. Thus, labor and capital input into the transmission subsector in the original data set are distributed to the four power generation subsectors, i.e., nuclear, thermal, hydro, and renewable energy.

Moreover, the intermediate inputs into the transmission subsector are also distributed to the four power generation subsectors, because the transmission subsector is in charged only of collecting generated electricity from the power generation subsectors and supplying to the demands including intermediates. We also should note that the four power generation subsectors deal only with the transmission subsector and there are no transactions between power generation and other industries and final demand in this model. Therefore, the raw-column balance in the four power generation subsectors is not considered.

\subsection{Supply side}

The production in the model consists of three stages (see Fig. 1). Firstly, the four power generation subsectors, S12-2 to S12-5, generate electricity using labor, capital, and intermediates including fuels. Secondly, the transmission subsector, S12-1, collects electricity from the power generations and distributes to the industries and the final demands. Thirdly, other eleven industrial sectors, S01-S11, produce using intermediates including electricity, labor, and capital inputs and supply their output to meet the demands.

\subsubsection{Electricity generation}

According to the framework of Input-Output analysis, production costs of electricity generation subsectors are given by the function 


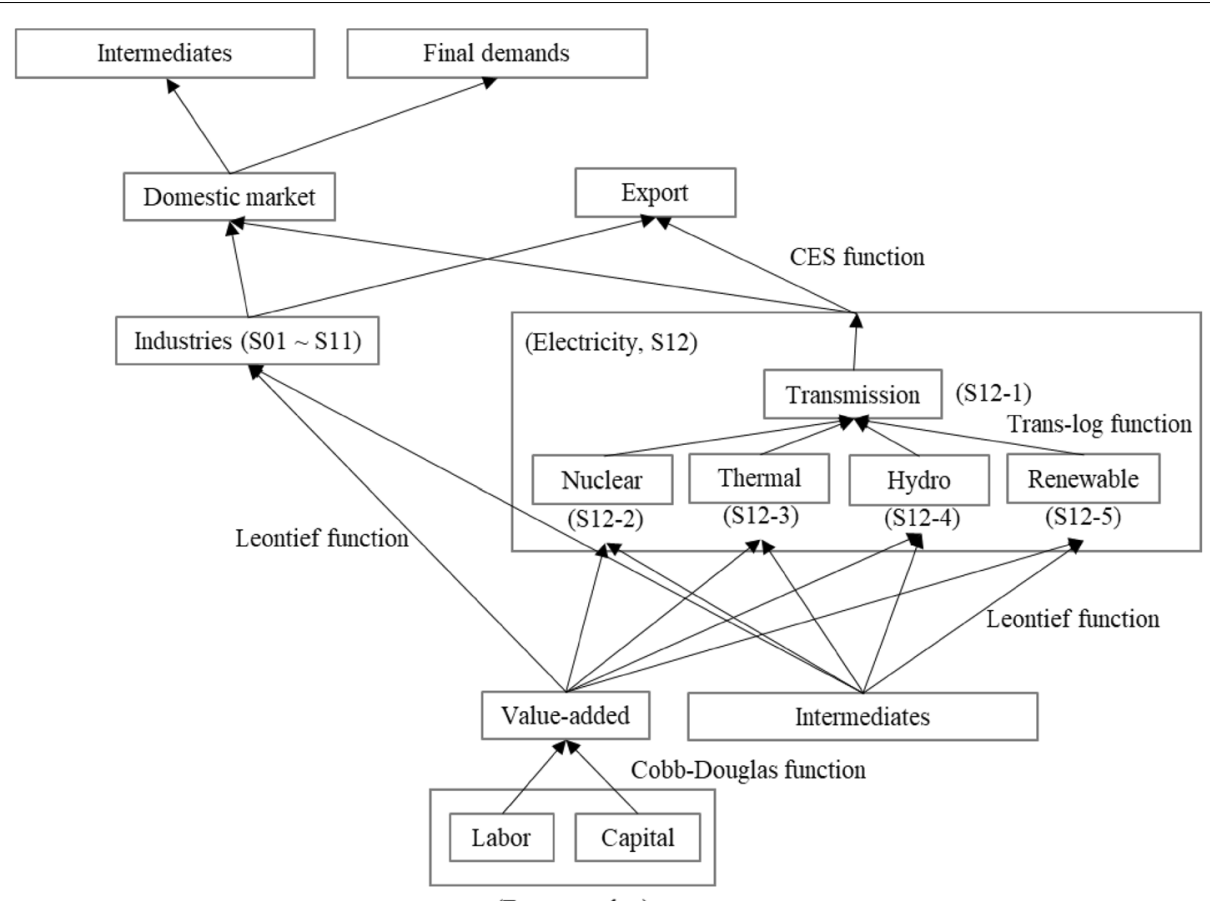

Fig. 1 Diagram of production

$$
p_{Z h} Z_{h}=\sum_{n} p_{Q n} a_{n h} Z_{n}+p_{V h} V_{h}
$$

where the subscripts $h=N, T, H, R$ indicate power generation using nuclear, thermal, hydro, and renewable energy, respectively, and $n=1-12$ indicate industrial sectors from the agriculture and fishing (S01) to the transmission (S12-1). Moreover, $V$ is valueadded that is produced by labor and capital input, $a_{n h}$ is the input coefficient of sector $h$ from $n$, and $p_{Q n}$ is the domestic market price of the $n$th commodity. The electricity generated by each subsector, $Z_{h}$, is assumed to be produced by the Leontief technology. Then, the producer's price of electricity, $p_{Z h}$, is determined by

$$
p_{Z h}=\sum_{n} a_{n h} p_{Q n}+a_{V h} p_{V h}
$$

where $a_{V h}=V_{h} / Z_{h}$ is the value-added rate of the power generation subsector $h, p_{V h}$ is value-added deflator of the power generation subsector $h .^{2}$ Value-added is produced following the Cobb-Douglas production function.

$$
V_{h}=\alpha_{h} K_{h}^{\beta_{h}} L_{h}^{1-\beta_{h}}
$$

Here, the capital input is calculated from profit-maximizing conducted with value-added as follows.

\footnotetext{
${ }^{2}$ Note that Eq. (2) is the dual cost function to the Leontief production function.
} 


$$
K_{h}=\beta_{h} p_{V h} V_{h} / p_{K}
$$

where $K$ is capital input, $p_{K}$ is the price of capital. Labor input is also derived as the same equation with Eq. (4).

\subsubsection{Transmission}

The transmission subsector is devoted to the distribution of electricity that is received from power generation subsectors. Then, the output of transmission subsector, $Z e$, is measured by the amounts of electricity sent to final customers, while its inputs are electricity generated by four sources, i.e., $Z_{N}, Z_{T}, Z_{H}$, and $Z_{R}$. Assuming the technology exhibits constant returns to scale, we have the unit cost function of the transmission subsector as

$$
p_{Z e}=f\left(p_{Z N}, p_{Z T}, p_{Z H}, p_{Z R}\right)
$$

where $p_{z i}, i=e, N, T, H, R$, are the corresponding unit cost of electricity. Behind Eq. (5), transmission subsector is assumed to minimize total transmission costs subject to technological restrictions given by (5). Equation (5) represents the inter-source substitutability and complementarity of electricity that are due to maintaining the stability of network in voltage and frequency at any moment. Since the unit cost function is linearly homogeneous in the unit costs of inputs, applying the Shephard's lemma to Eq. (5) yields

$$
p_{Z e} Z_{e}=\sum_{h} p_{Z h} Z_{h}
$$

We employ the translog form to specialize Eq. (5) as ${ }^{3}$

$$
\ln p_{Z e}=\sum_{h} \alpha_{h} \ln \left(1+\tau_{Z h}+\tau_{C h}\right) p_{Z h}+0.5 \sum_{h^{\prime}} \sum_{h} \beta_{h^{\prime} h} \ln \left(1+\tau_{Z h^{\prime}}+\tau_{C h^{\prime}}\right) p_{Z h^{\prime}} \ln \left(1+\tau_{Z h}+\tau_{C h}\right) p_{Z h}
$$

where $\tau_{Z h}$ and $\tau_{C h}$ are indirect tax rate and carbon tax rate on power source $h$, respectively. The Shephard's lemma is applied to Eq. (7) to obtain the following cost share equations

$$
S_{h}=\alpha_{h}+\sum_{h^{\prime}} \beta_{h^{\prime} h} \ln \left(1+\tau_{Z h^{\prime}}+\tau_{C h^{\prime}}\right) p_{Z h^{\prime}}
$$

where $S_{h}$ is defined as $\left(1+\tau_{Z h}+\tau_{C h}\right) p_{Z h} Z_{h} / \sum_{h^{\prime}} p_{Z h^{\prime}} Z_{h^{\prime}}$. Then, the amount of electricity generated by each source is described as

$$
Z_{h}=S_{h} p_{Z e} Z_{e} /\left(1+\tau_{Z h}+\tau_{C h}\right) p_{Z h}
$$

Although most of the previous CGE studies employ the CES function, the CES form does not allow complementary relationships among inputs. In this paper, we consider the possibility of complementarity among power sources, for example, complementarity between renewable energy and nuclear power as well as substitutability. We thus prefer more flexible translog form over CES function to model technological restrictions imposed on the operation of the electric power system.

\footnotetext{
${ }^{3}$ By the symmetric condition, $\beta_{h^{\prime} h}=\beta_{h h^{\prime}}$.
} 


\subsubsection{Industry sectors except for power generation and transmission}

The production of industrial sectors except the electricity is modeled by Leontief technology. The following two equations are basically the same as Eqs. (1) and (2). That is,

$$
p_{Z i} Z_{i}=\sum_{j} p_{Q j} a_{j i} Z_{i}+p_{Q e} a_{e i} Z_{i}+p_{V i} V_{i}
$$

where, $i, j=\mathrm{S} 01-\mathrm{S} 11$ is industrial sectors except electricity related. Their producer's price, $p_{Z i}$, is

$$
p_{Z i}=\sum_{j} a_{j i} p_{Q j}+a_{e i} p_{Q e}+a_{V i} p_{V i}
$$

The meaning of each parameter in Eqs. (10) and (11) is the same within Eqs. (1) and (2). Moreover, labor, capital, and production of value-added of $i$ th sector follow the CobbDouglas technology as Eqs. (3) and (4).

\subsubsection{Distribution of production into the domestic market and export}

This study assumes that domestic supply and export are not perfect substitutes. Under the imperfect substitution, $n$th output, $Z_{n}$, follows a CET function shown as Eq. (12) and supply to domestic market, $\mathrm{DS}_{n}$, and export, $\mathrm{EX}_{n}$, are derived from profit maximization as Eqs. (13) and (14).

$$
\begin{aligned}
& Z_{n}=\theta_{n}\left(\xi_{\mathrm{Dn}} \mathrm{DS}_{n}^{\phi_{n}}+\xi_{\mathrm{En}} \mathrm{EX}_{n}^{\phi_{n}}\right)^{\frac{1}{\phi_{n}}} \\
& \mathrm{DS}_{n}=\left(\frac{\xi_{D n} \theta_{n}^{\phi_{n}}\left(1+\tau_{Z n}+\tau_{C n}\right) p_{Z n}}{p_{D n}}\right)^{\frac{1}{1-\phi_{n}}} Z_{n} \\
& \mathrm{EX}_{n}=\left(\frac{\xi_{E n} \theta_{n}^{\phi_{n}}\left(1+\tau_{Z n}+\tau_{C n}\right) p_{Z n}}{p_{E n}}\right)^{\frac{1}{1-\phi_{n}}} Z_{n}
\end{aligned}
$$

where $\tau_{Z n}$ and $\tau_{C n}$ are indirect tax rate and carbon tax rate imposed on the $n$th production process, respectively. We should note that $\tau_{Z n}$ and $\tau_{C n}$ on transmission subsector, $n=\mathrm{S} 12-1$, is zero. $p_{D n}$ and $p_{E n}$ are domestic price and export price of the $n$th commodity, respectively. $\theta_{n}, \phi_{n}, \xi_{D n}$, and $\xi_{E n}$ are parameters. $\phi_{n}$ is statistically estimated by using the annual SNA input-output table ${ }^{4}$ reported by Cabinet office of Japan from 2001 to 2013. Other parameters are set to satisfy the data set, SAM in 2005 based on the Waseda university's input-output table.

\subsection{Demand-side}

\subsubsection{Government behavior}

Revenue of government consists of income tax imposed on households, indirect tax and carbon tax imposed on the production process, and import tariff, as shown in Eq. (15).

\footnotetext{
${ }^{4}$ http://www.esri.cao.go.jp/jp/sna/data/data_list/sangyou/files/files_sangyou.html.
} 


$$
\mathrm{INC}_{G}=\mathrm{IT}+\mathrm{IDT}+\mathrm{CT}+\mathrm{IMT}+\mathrm{CAS}
$$

Firstly, CAS is a current-account surplus in 2005 reflected in government fiscal accounting to balance the sum of rows and columns in SAM, as mentioned in Sect. 2.1, and CAS is fixed in this simulation. IT is household income tax. Since household income is accrued from supplying labor and capital inputs to the eleven industrial sectors the four power generation subsectors, we then have the following equation.

$$
\mathrm{IT}=\tau_{H}\left(\sum_{i}\left(p_{K} K_{i}+P_{L} L_{i}\right)+\sum_{h}\left(p_{K} K_{h}+p_{L} L_{i}\right)\right)
$$

$\tau_{H}$ is the income tax rate. IDT is an indirect tax and calculated as follows.

$$
\mathrm{IDT}=\sum_{n} \tau_{Z n} p_{Z n} Z_{n}
$$

CT means a total carbon tax. Generally, a carbon tax is imposed on carbon (C) emission, not on carbon dioxide $\left(\mathrm{CO}_{2}\right)$. In this study, however, a carbon tax is assumed to be imposed on $\mathrm{CO}_{2}$ emission because of lack of available data. Moreover, $\mathrm{CO}_{2}$ emission in Japan is assumed in our model to emit stems from fossil fuel input. Since final demand for fossil fuel is negligible compared to intermediate input in the original data, $\mathrm{CO}_{2}$ emission is calculated from only an intermediate input of fossil in the suggested model. According to Greenhouse gas Inventory Office of Japan (GIO), ${ }^{5} \mathrm{CO}_{2}$ emission in 2005 is 1290 million ton (Mton). Therefore, $\mathrm{CO}_{2}$ emission per unit input of fossil fuel (ton/Yen) is,

$$
U \mathrm{CO}_{2}=1290 / \sum_{n} a_{2 n} Z 0_{n}
$$

where subscript number 2 indicates the fossil fuel sector and $Z 0_{n}$ is the initial value of output (million Yen) of each industrial sector. Thus, the denominator of the right-hand side of Eq. (18) is the total intermediate input of fossil fuel.

Based on Eq. (18), $\mathrm{CO}_{2}$ emission per unit production of $n$th industry (ton/Yen) is,

$$
\mathrm{CO}_{2_{n}}=a_{2 n} U \mathrm{CO}_{2}=a_{2 n} 1290 / \sum_{n} a_{2 n} Z 0_{n}
$$

Moreover, the carbon tax rate on the $n$th industry, $\tau_{C n}$, is obtained by multiplying $\mathrm{CO}_{2_{n}}$ in Eq. (19) and carbon tax per unit emission (Yen/ton). From these, the total carbon tax, CT, in Eq. (15) is derived by summation of the carbon tax on each sector.

$$
\mathrm{CT}=\sum_{n} \tau_{C n} p_{Z n} Z_{n}
$$

Finally, the import tariff, IMT, is,

$$
\mathrm{IMT}=\sum_{n} \tau_{M n} p_{M n} I M_{n}
$$

\footnotetext{
${ }^{5}$ The same data is found also at website of Japan Center for Climate Change Actions. http://www.jccca.org/chart/chart 04_03.html.
} 
where $\tau_{M n}$ is import tariff rate of the $n$th commodity, $p_{M n}$ is import price, and $\mathrm{IM}_{n}$ is an import, respectively. Government consumes based on the tax income as follows.

$$
C_{G n}=\alpha_{G n}\left(1-s_{G}\right) \mathrm{INC}_{G} / p_{Q n}
$$

where $C_{G n}$ is the government's demand for the $n$th commodity, $\alpha_{G n}$ is government consumption rate for the $n$th commodity, and $s_{G}$ is government saving rate, respectively.

\subsubsection{Household behavior}

Households' income consists of wage and capital income. Households' consume commodities based on their disposable income that is the rest of total income subtracted income tax and savings. Households' consumption behavior is based on their utility maximization, and the utility function is shown as following Cobb-Douglas function.

$$
U=\prod_{n} C_{H n}^{\alpha_{H n}}
$$

where $U$ is households' utility, $C_{H n}$ is households' consumption for the $n$th commodity, and $\alpha_{H n}$ is the ratio of the demand for the $n$th commodity to households' total demand. From Eq. (23), $C_{H n}$ is derived as following Eq. (24) by utility maximization.

$$
C_{H n}=\alpha_{H n}\left(1-\tau_{H}-s_{H}\right)\left\{\sum_{i}\left(p_{K} K_{i}+P_{L} L_{i}\right)+\sum_{h}\left(p_{K} K_{h}+p_{L} L_{i}\right)\right\} / p_{Q} n
$$

where $s_{H}$ is the households' saving rate.

\subsubsection{Investment behavior}

This study assumes that investment behavior is based on the total saving of the economy. Total saving of the economy consists of government's saving, the households' saving, and foreign saving which indicates a current-account deficit. First, the government's saving and households' saving are,

$$
\begin{aligned}
& S_{G}=s_{G}(\mathrm{IT}+\mathrm{IDT}+\mathrm{CT}+\mathrm{IMT}+\mathrm{CAS}) \\
& S_{H}=s_{H}\left\{\sum_{i}\left(p_{K} K_{i}+P_{L} L_{i}\right)+\sum_{h}\left(p_{K} K_{h}+p_{L} L_{i}\right)\right\}
\end{aligned}
$$

Moreover, current-account balancing is,

$$
\sum_{n} p_{E n}^{W} \mathrm{EX}_{n}+S_{f}=\sum_{n} p_{M n}^{W} \mathrm{IM}_{n}
$$

where $p_{E n}^{W}$ is the export price of the $n$th commodity in terms of dollar, $p_{M n}^{W}$ is import price in terms of dollar, and $S_{f}$ is foreign saving, i.e., current-account deficit, in terms of the dollar. From above, the total savings of the economy is,

$$
S=S_{G}+S_{H}+\varepsilon S_{f}
$$

$\varepsilon$ in Eq. (28) is the exchange rate (Yen/Dollar). Investment for the $n$th industry is,

$$
C_{I n}=\lambda_{n}\left(S_{G}+S_{H}+\varepsilon S_{f}\right) / p_{Q n}
$$




\subsubsection{Allocation of total demand for the domestic commodity and imported commodity}

Total demand for the $n$th commodity, $Q_{n}$, consists of households' consumption, government's consumption, investment, and intermediate input.

$$
Q_{n}=C_{H n}+C_{G n}+C_{I n}+\sum_{i} a_{n i} Z_{i}+\sum_{h} a_{n h} Z_{h}
$$

This paper assumes the demand for the imported commodity and domestic commodity are imperfect substitution similar to Sect. 2.2.4. Based on this assumption, $Q_{n}$ is shown as the following Eq. (31), an Armington function. Moreover, the demand for the domestic commodity, $\mathrm{DS}_{n}$, and the demand for the imported commodity, $\mathrm{IM}_{n}$, can be obtained from profit maximization.

$$
\begin{aligned}
& Q_{n}=\gamma_{n}\left(\delta_{D n} D S_{n}^{\eta_{n}}+\delta_{M n} I M_{n}^{\eta_{n}}\right)^{\frac{1}{\eta_{n}}} \\
& \mathrm{DS}_{n}=\left(\frac{\delta_{D n} \gamma_{n}^{\eta_{n}} p_{Q_{n}}}{p_{D n}}\right)^{\frac{1}{1-\eta_{n}}} Q_{n} \\
& \mathrm{IM}_{n}=\left(\frac{\delta_{M n} \gamma_{n}^{\eta_{n}} p_{Q_{n}}}{\left(1+\tau_{M}\right) p_{M n}}\right)^{\frac{1}{1-\eta_{n}}} Q_{n}
\end{aligned}
$$

$\gamma_{n}, \delta_{D n}, \delta_{M n}$, and $\eta_{n}$ are parameters. $\eta_{n}$, like as $\phi_{n}$ in Eqs. (12)-(14), is estimated from the SNA input-output table reported by Cabinet office of Japan from 2001 to 2013. Other 3 parameters are determined to satisfy the original data set, the expanded input-output table in 2005.

\section{Parameter determination}

\subsection{Parameter estimation of CES function}

As mentioned, parameters $\phi_{n}$ and $\eta_{n}$ are estimated from SNA input-output table of Cabinet office of Japan using OLS estimation. The estimated results are shown in Tables 2 and 3. Note that the values of the construction sector (S08), the gas-heatwater-waste sector (S10), and the electricity (S12) are arbitrarily set to prevent 0 divided, because the export and import of these three sectors are null or negligibly small.

Table 2 Estimation of substitution parameter of CET function, $\phi_{n}$

\begin{tabular}{lllllll}
\hline Industrial sector $(\boldsymbol{n})$ & S01 & S02 & S03 & S04 & S05 & S06 \\
\hline$\phi_{n}$ & 0.17379 & 0.14533 & 0.43175 & 0.26086 & 0.49118 & 0.81650 \\
\hline Industrial sector $(\boldsymbol{n})$ & S07 & S08 & S09 & S10 & S11 & S12 \\
\hline$\phi_{n}$ & 0.89777 & 0.01000 & 0.50755 & 0.01000 & 0.24216 & 0.01000 \\
\hline S01-S12 are the identifying numbers indicating industrial sectors shown in Table 1
\end{tabular}


Table 3 Estimation of substitution parameter of Armington function, $\eta_{n}$

\begin{tabular}{lllllll}
\hline Industrial sector $(\boldsymbol{n})$ & S01 & S02 & S03 & S04 & S05 & S06 \\
\hline$\eta_{n}$ & 0.58905 & 0.18119 & 0.48149 & 0.58294 & 0.55616 & 0.43139 \\
\hline Industrial sector $(\boldsymbol{n})$ & S07 & S08 & S09 & S10 & S11 & S12 \\
\hline$\eta_{n}$ & 0.84518 & 0.01000 & 0.38359 & 0.01000 & 0.20083 & 0.01000 \\
\hline S01-S12 are the identifying numbers indicating industrial sectors shown in Table 1 &
\end{tabular}

\subsection{Parameter determination of translog function}

This study uses Allen elasticity of substitution to investigate the effect of carbon tax on the power generation in the substitution-complement relationship between renewable energy and other conventional power sources. We can obtain the own-price and crossprice Allen elasticity of substitution from the initial value, expanded input-output table in 2005 .

$$
\begin{gathered}
\sigma_{h h^{\prime}}=\frac{\beta_{h^{\prime} h}+S_{h}^{0} S_{h^{\prime}}^{0}}{S_{h}^{0} S_{h^{\prime}}^{0}} \\
\sigma_{h h}=\frac{\beta_{h h}-S_{h}^{0}+\left(S_{h}^{0}\right)^{2}}{\left(S_{h}^{0}\right)^{2}}
\end{gathered}
$$

where $S_{h}^{0}$ is initial cost share of the $h$ th power source. Two inputs are substitutes (complements) when Allen elasticity of substitution is positive (negative), and Allen elasticity of substitution are given exogenously. The exogenous Allen elasticity of substitution is shown in Table 4. Then, we can calculate $\beta_{h^{\prime} h}$ and $\beta_{h h}$ in Eqs. (34) and (35) from exogenous Allen elasticity of substitution and initial cost share. Finally, to simplify the determination of parameter $\alpha_{h}$, we assume that the logarithm term in Eq. (8) is zero in the initial condition. Then, we have

$$
\alpha_{h}=S_{h}^{0}=\frac{Z_{h}^{0}}{Z_{e}^{0}}, \quad Z_{e}^{0}=\sum_{h} Z_{h}^{0}
$$

Table 4 Allen elasticity of substitution among power sources in substitutional scenarios

\begin{tabular}{lrrrrlrrrr}
\hline Scenario 1 & \multicolumn{1}{l}{$\boldsymbol{N}$} & \multicolumn{1}{l}{$\boldsymbol{T}$} & $\boldsymbol{H}$ & $\boldsymbol{R}$ & Scenario 2 & $\boldsymbol{N}$ & $\boldsymbol{T}$ & $\boldsymbol{H}$ & \multicolumn{1}{c}{$\boldsymbol{R}$} \\
\hline$N$ & -1.00 & 1.25 & 1.25 & 2.50 & $N$ & -1.00 & 1.25 & 1.25 & -2.50 \\
$T$ & 1.25 & -1.00 & 1.25 & 5.00 & $T$ & 1.25 & -1.00 & 1.25 & 5.00 \\
$H$ & 1.25 & 1.25 & -1.00 & 2.50 & $H$ & 1.25 & 1.25 & -1.00 & -2.50 \\
$R$ & 2.50 & 5.00 & 2.50 & -1.00 & $R$ & -2.50 & 5.00 & -2.50 & -1.00 \\
\hline
\end{tabular}

To assume the elasticity of substitution, we consulted Wissema and Dellink (2007) and Benavente (2016)

$N, T, H$, and $R$ indicate nuclear, thermal, hydro, and renewable power generation, respectively 
Table 5 Change rate (\%) of production of each industrial sector S01-S11

\begin{tabular}{|c|c|c|c|c|c|c|}
\hline \multirow{2}{*}{$\begin{array}{l}\text { Industrial } \\
\text { sectors }\end{array}$} & \multicolumn{3}{|c|}{ Scenario 1 (substitution) } & \multicolumn{3}{|c|}{ Scenario 2 (complement) } \\
\hline & 289 Yen (BAU) & 600 Yen & 2000 Yen & 289 Yen (BAU) & 600 Yen & 2000 Yen \\
\hline S01 & -0.064 & -0.133 & -0.449 & -0.064 & -0.134 & -0.452 \\
\hline S02 & -0.241 & -0.497 & -1.635 & -0.240 & -0.495 & -1.631 \\
\hline S03 & -0.045 & -0.094 & -0.312 & -0.046 & -0.095 & -0.314 \\
\hline SO4 & -0.062 & -0.129 & -0.435 & -0.063 & -0.130 & -0.438 \\
\hline S05 & -0.266 & -0.551 & -1.815 & -0.266 & -0.551 & -1.816 \\
\hline S06 & -0.057 & -0.118 & -0.387 & -0.057 & -0.119 & -0.388 \\
\hline S07 & -0.067 & -0.139 & -0.456 & -0.067 & -0.139 & -0.457 \\
\hline S08 & -0.012 & -0.025 & -0.087 & -0.012 & -0.026 & -0.089 \\
\hline S09 & -0.059 & -0.123 & -0.411 & -0.059 & -0.123 & -0.413 \\
\hline S10 & -0.116 & -0.241 & -0.795 & -0.117 & -0.242 & -0.797 \\
\hline S11 & 0.028 & 0.057 & 0.188 & 0.028 & 0.057 & 0.186 \\
\hline
\end{tabular}

S01-S11 are the identifying numbers indicating industrial sectors shown in Table 1

\section{Results and discussion ${ }^{6}$}

\subsection{Simulation description}

As mentioned in Sect. 1, the effect of carbon tax on power generation is analyzed using suggested CGE model in a substitution scenario and a complement scenario, as an application of the model. For carbon tax, three carbon tax scenarios are assumed, that is 289 $\mathrm{Yen} / \mathrm{CO}_{2}$ ton, $600 \mathrm{Yen} / \mathrm{CO}_{2}$ ton, and $2000 \mathrm{Yen} / \mathrm{CO}_{2}$ ton, respectively. The Japanese government is already imposing carbon tax named 'Global warming countermeasure tax', as $289 \mathrm{Yen} / \mathrm{CO}_{2}$ ton (Ministry of Environment of Japan). Therefore, three carbon tax scenarios indicate business as usual (BAU), two times of present, and seven times of present, respectively. Since other literature (e.g., Benavente 2016) test their model assuming carbon tax higher than 50 US dollar per ton, our suggesting carbon tax scenarios are reasonable.

Scenario 1 in Table 4 is substitution scenario. Firstly, the substitutability between thermal and nuclear, thermal and hydro, and nuclear and hydro are 1.25. The elasticity of substitution between renewable energy and nuclear, and renewable energy and hydro is 2.50. Only the value between thermal and renewable energy is high, 5.00.

Scenario 2 in Table 4 shows a complementary scenario. In this case, the relationship among the three conventional power sources and between thermal power generation and renewable energy is substituted as scenario 1 . The only difference is the elasticity of substitution of renewable energy for nuclear power and hydropower (these are -2.50). This case means that nuclear and hydropower generation act as back-up loads for renewable energy, while renewable energy acts as a base load in scenario 1 .

\subsection{Simulation results}

Since the change of production of 11 industrial sectors under the three carbon tax scenarios is similar in substitution and complement cases, in this section, the discussion for

\footnotetext{
${ }^{6}$ In order to investigate the robustness of the model, a sensitivity test for the parameter of the translog function (see Eq. (7)) is conducted. For the sensitivity test, the parameter value is adjusted as $10 \%$ up/down and $5 \%$ up/down. The robustness of the model is confirmed as the optimal solutions are merely changed. Therefore, we regard the model stable and proceed scenario analysis. For the results of the sensitivity text, see "Appendix A".
} 


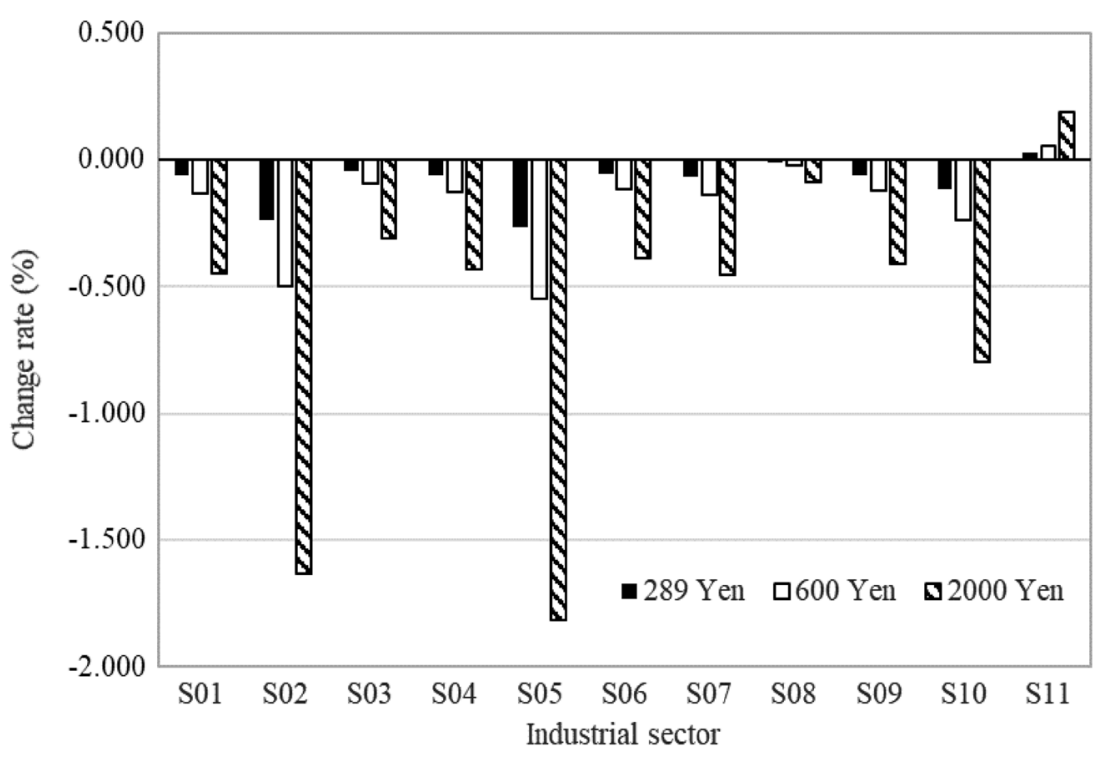

Fig. 2 The change rate of production of each sector in scenario 1 (substitution)

Table 6 Change rate (\%) of electricity generation

\begin{tabular}{|c|c|c|c|c|c|c|}
\hline \multirow[t]{2}{*}{ Industrial sectors } & \multicolumn{3}{|c|}{ Scenario 1 (substitution) } & \multicolumn{3}{|c|}{ Scenario 2 (complement) } \\
\hline & 289 Yen (BAU) & 600 Yen & 2000 Yen & 289 Yen (BAU) & 600 Yen & 2000 Yen \\
\hline Transmission & -0.037 & -0.077 & -0.259 & -0.021 & -0.043 & -0.150 \\
\hline Nuclear & 0.463 & 0.961 & 3.194 & 0.482 & 1.000 & 3.321 \\
\hline Thermal & -0.391 & -0.809 & -2.658 & -0.375 & -0.777 & -2.554 \\
\hline Hydro & 0.505 & 1.048 & 3.484 & 0.527 & 1.093 & 3.633 \\
\hline Renewable & 2.304 & 4.788 & 16.038 & 2.111 & 4.388 & 14.703 \\
\hline
\end{tabular}

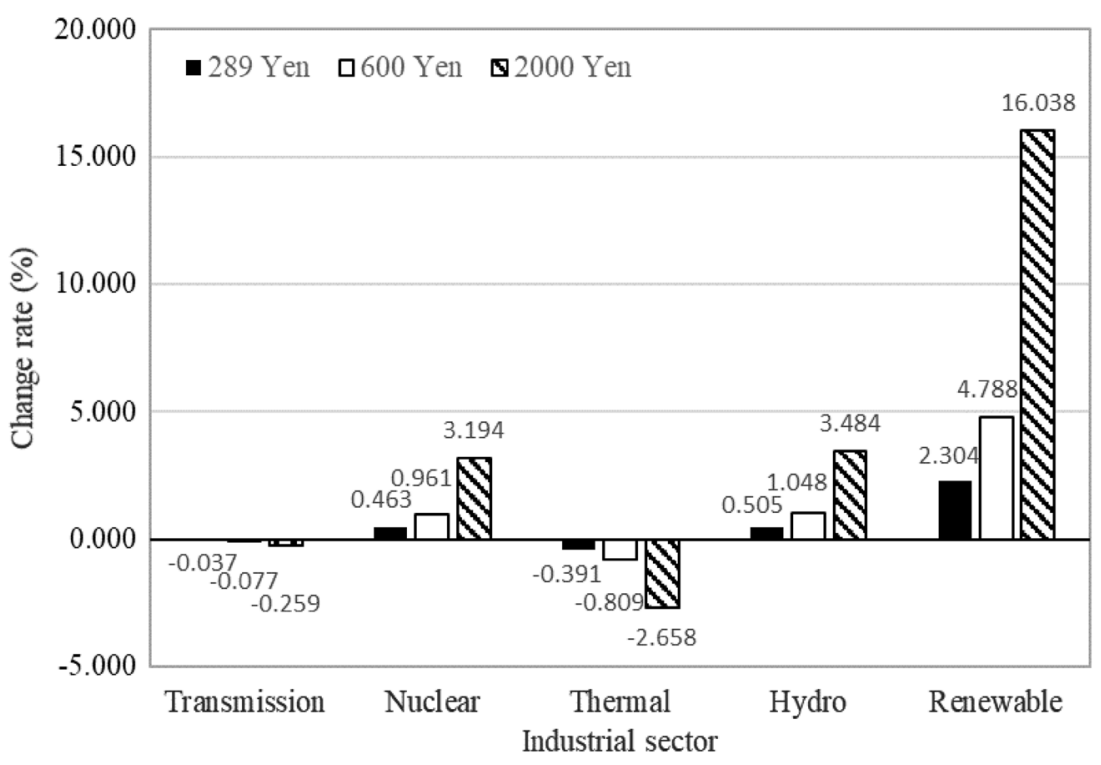

Fig. 3 The change rate of electricity generation in scenario 1 (substitution) 


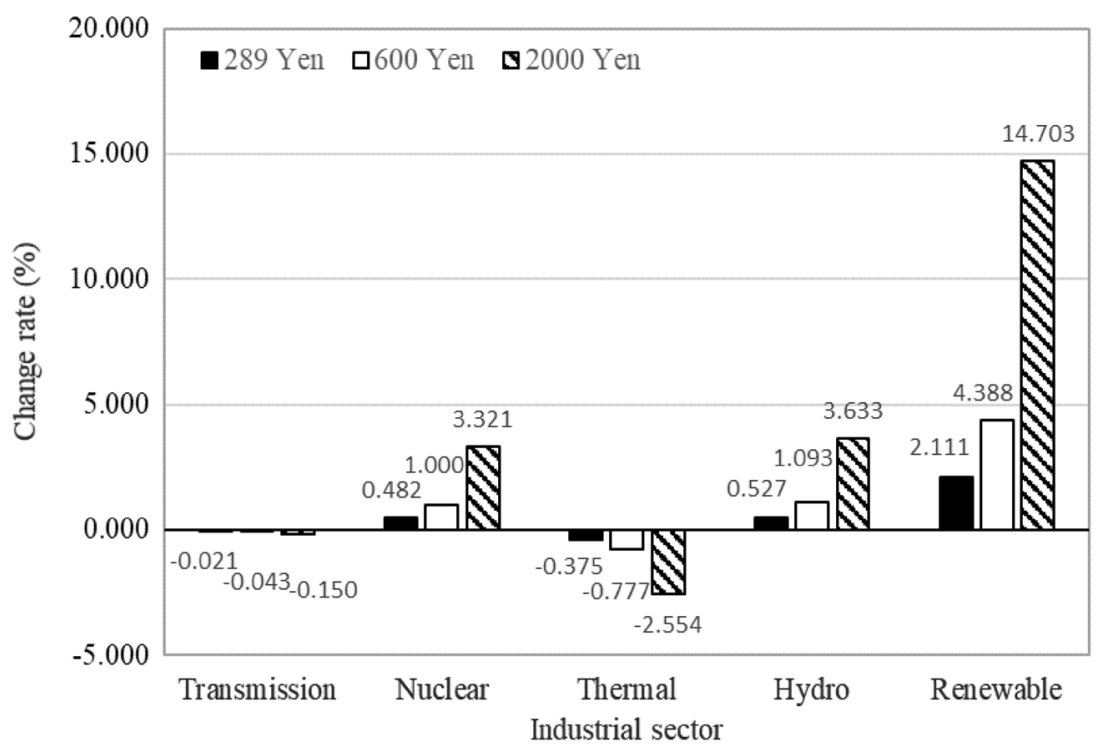

Fig. 4 The change rate of electricity generation in scenario 2 (complement)

the 11 industrial sectors in complement scenario is omitted. As shown in Table 5 and Fig. 2, productions of sectors except for other services (S11) are reduced by the carbon tax, and the reduction rate becomes more prominent as the carbon tax increasing. This is consistent with other literature concerning carbon tax. The increase in production of other services (S11) can be attributed to the additional government revenue from the carbon tax since the government's consumption for other services is substantial.

The result shows that carbon tax induces the substitution of power sources for thermal power generation (see scenario 1 in Table 6 and Fig. 3). The substitution becomes significant as carbon tax increasing. For example, thermal power generation is decreased by $0.391 \%$, and nuclear, hydro and renewable energy are increased by $0.463 \%, 0.505 \%$, and $2.304 \%$, respectively, in BAU case, while it becomes remarkable by $2000 \mathrm{Yen} / \mathrm{CO} 2$ ton of carbon tax (nuclear 3.194\%, thermal $-2.658 \%$, hydro 3.484\%, and renewable $16.038 \%$, respectively). Despite the substitution, the total production of the electricity industry is decreased, because the share of thermal power generation is the biggest among the power sources.

In the complementary scenario (scenario 2), substitution of renewable energy for thermal power generation is less than that in the substitution scenario (scenario 1). On the other hand, the change rate of nuclear and hydro in power generation becomes higher (see scenario 2 in Table 6 and Fig. 4). As mentioned, scenario 2 indicates that nuclear and hydropower generation is back-up loads for renewable energy. Therefore, this result shows that the capacity expansion of back-up loads is necessary to increase renewable energy use. Carbon tax induces substitution of renewable energy for thermal power generation, and renewable energy use in power generation increases. In scenario 2 , the expansion of renewable energy requires nuclear and hydropower generation as its backup. Thus, a part of the substitution of renewable energy is shifted. 
Table 7 Change rate (\%) of GDP of each sector (S01-S11, N, T, H, R)

\begin{tabular}{|c|c|c|c|c|c|c|}
\hline \multirow[t]{2}{*}{ Industrial Sectors } & \multicolumn{3}{|c|}{ Scenario 1 (substitution) } & \multicolumn{3}{|c|}{ Scenario 2 (complement) } \\
\hline & 289 Yen (BAU) & 600 Yen & 2000 Yen & 289 Yen (BAU) & 600 Yen & 2000 Yen \\
\hline S01 & -0.064 & -0.133 & -0.449 & -0.064 & -0.134 & -0.452 \\
\hline SO2 & -0.239 & -0.496 & -1.634 & -0.239 & -0.495 & -1.630 \\
\hline S03 & -0.045 & -0.094 & -0.312 & -0.046 & -0.095 & -0.314 \\
\hline S04 & -0.062 & -0.129 & -0.435 & -0.063 & -0.130 & -0.438 \\
\hline S05 & -0.266 & -0.551 & -1.815 & -0.266 & -0.551 & -1.816 \\
\hline S06 & -0.057 & -0.118 & -0.387 & -0.057 & -0.119 & -0.388 \\
\hline S07 & -0.067 & -0.139 & -0.456 & -0.067 & -0.139 & -0.457 \\
\hline S08 & -0.012 & -0.025 & -0.087 & -0.012 & -0.026 & -0.089 \\
\hline S09 & -0.059 & -0.123 & -0.411 & -0.059 & -0.123 & -0.413 \\
\hline S10 & -0.116 & -0.241 & -0.795 & -0.117 & -0.241 & -0.797 \\
\hline S11 & 0.028 & 0.056 & 0.189 & 0.025 & 0.056 & 0.186 \\
\hline Nuclear & 0.463 & 0.961 & 3.193 & 0.482 & 1.000 & 3.321 \\
\hline Thermal & -0.391 & -0.809 & -2.658 & -0.375 & -0.777 & -2.554 \\
\hline Hydro & 0.505 & 1.048 & 3.484 & 0.527 & 1.093 & 3.633 \\
\hline Renewable & 2.304 & 4.787 & 16.039 & 2.107 & 4.381 & 14.698 \\
\hline
\end{tabular}

S01-S11 are the identifying numbers indicating industrial sectors shown in Table 1

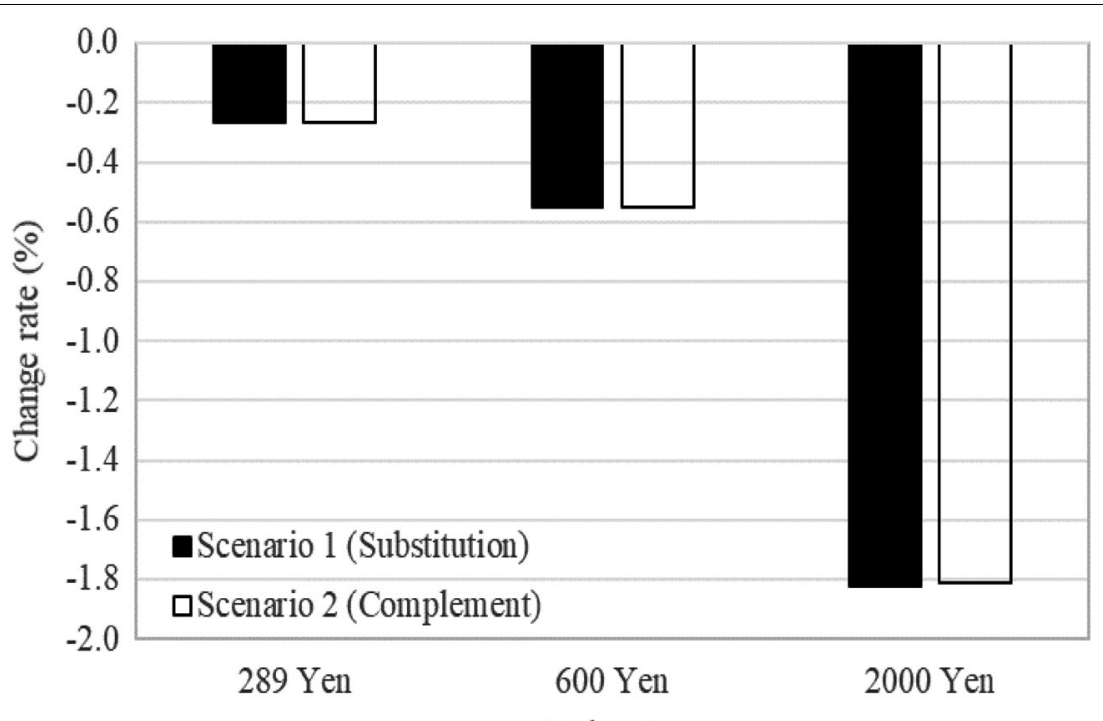

Carbon tax

Fig. 5 The change rate of $\mathrm{CO}_{2}$ emission under the carbon tax

\subsection{Change in GDP and $\mathrm{CO}_{2}$ emission}

Table 7 shows that the changes in GDP in all cases are negligible. This is attributed to firstly, compensation of the government consumption for other services (S11) to the negative effect of carbon tax on the production (i.e., demand reduction caused by the increase in cost), and secondly, substitution of the increase in labor and capital input for the reduction in the production.

Figure 5 shows that carbon tax merely reduces $\mathrm{CO}_{2}$ emission in the entire economy in both scenarios. Even in the case of $2000 \mathrm{Yen} / \mathrm{CO}_{2}$ ton, $\mathrm{CO}_{2}$ emission is reduced by only 
$1.8 \%$. This implies that in Japan, a carbon tax is not an effective policy for $\mathrm{CO}_{2}$ reduction. Japan is technologically progressed country. Therefore, it seems that this result implies effective production in the perspective of $\mathrm{CO}_{2}$ emission may have achieved, even in 2005. Thus, other policies, for example, emission trading, are necessary to accomplish the emission target.

\section{Conclusion}

This paper suggests another type of CGE model that uses the translog function for modeling of power generation. As an application of the suggested model, the effects of the carbon tax on power generation in substitution and complement scenarios are investigated. To investigate the carbon tax effect in each case, three carbon tax scenarios (289 Yen as BAU, 600 Yen, and 2000 Yen/CO $\mathrm{CO}_{2}$ ton) are compared. The results of the simulation show that industrial production is decreasing and substitution of the power sources for thermal power generation is significant as the carbon tax increases. Moreover, the result suggests that the translog function model is available for analysis of electricity industry under environmental policies.

Table 6, Figs. 3 and 4 show small differences between scenario 1 (substitution) and scenario 2 (complement). This paper does not assume extremely high or low elasticity of substitution among the power source. Therefore, the results are shown in this study reflect a realistic situation, and these small differences do not undermine the value of our model. Above all, while the multi-layered CES model needs assumptions about the aggregate structure, the translog model does not, because this is second order Taylor approximation of any function.

The major contribution of this is to introduce flexible translog function in the CGE modeling of power generation sectors. However, there are some challenges to the improvement in this model in further work. Firstly, the physical and economic characteristics of power sources should be reflected in the unit costs of power generation more accurately. For example, the nuclear power is not back-up loads for renewable energy if we consider the maintenance cost or shut down cost. By considering the characteristics of each power source, including environmental loads, the results in this paper is changeable and improvable. Secondly, this study uses the arbitrarily given elasticity of substitution. The estimation or observation of real elasticity of substitution among the power sources may be helpful.

Despite these challenges, the model is valuable in various researches of energy and environmental policy analysis as a flexible framework of policy studies. It is expected that the enhanced translog model can help to make realistic energy and environmental policies. The suggested translog function model can be used for other environmental researches. For example, we can investigate the effect of generation price increase in a power source on the electricity industry. Attempts to apply the translog function to various CGE modeling and policy analysis will improve the performance.

\section{Abbreviations}

CGE: computable general equilibrium; KEPC: Kyushu Electric Power Company; CES: constant elasticity of substitution SAM: social accounting matrix; SNA: system of national account; CET: constant elasticity of transformation; BAU: business as usual. 
Acknowledgements

The expanded input-output table used in this study is generated by Institute for Economic Analysis of Next-generation Science and Technology of Waseda University. The author thanks to professor Jiro Nemoto of Nagoya University for advices.

Authors' contributions

The major contribution is to apply translog function to CGE model, and to investigate power generations sector under carbon tax assuming substitution scenario and complement scenario. Moreover, the author contributes to estimation of elasticity of substitution in Armington function of Japanese industry.

Funding

The author declares that there is no finance assistance for this study.

Availability of data and materials

The expanded input-output table used in this article can be found at the website of Institute for Economic Analysis of Next-generation Science and Technology of Waseda University.

Competing interests

The author declares that he has no competing interests.

\section{Appendix A: The result of sensitivity test}

As mentioned in footnote 6 , the sensitivity test is conducted to check the robustness of the model. The result of sensitivity test is shown in Table 8. The values shown in the table are percentage change from the results of the calculation with original parameter. The sensitivity test is conducted under the no shock (i.e., carbon tax is zero) condition. As shown in the table, the percentage changes in the production of each sector converge as the variation in the parameter becomes small. This implies that model is stable. Note that the sensitivity test shown in this paper is practiced for the substitution scenario, but there is no significant change for the complement scenario.

\section{Appendix B: The results of additional simulation}

For the additional scenario, the elasticities of substitution between renewable energy and three other power sources in scenario 2 is doubled to confirm the results of the scenario. The adjusted elasticities of substitution are shown in Table 9, and the results of the simulation of the added scenario are shown in Fig. 6. Compared to Fig. 4 in Sect. 4, the

Table 8 The results of sensitivity test

\begin{tabular}{lrrrrrr}
\hline & $\mathbf{1 0} \%$ up & $\mathbf{1 0} \%$ down & \multicolumn{1}{l}{$\mathbf{5 \%}$ up } & $\mathbf{5 \% \text { down }}$ & $\mathbf{1 \%}$ up & $\mathbf{1 \% \text { down }}$ \\
\hline S01 & 0.00024 & -0.00023 & 0.00013 & -0.00011 & 0.00003 & -0.00002 \\
S02 & 0.01208 & -0.01208 & 0.00557 & -0.00650 & 0.00093 & -0.00186 \\
S03 & 0.00059 & -0.00058 & 0.00030 & -0.00029 & 0.00007 & -0.00005 \\
S04 & 0.00023 & -0.00021 & 0.00012 & -0.00010 & 0.00003 & -0.00001 \\
S05 & 0.00198 & -0.00197 & 0.00099 & -0.00099 & 0.00020 & -0.00020 \\
S06 & 0.00186 & -0.00186 & 0.00093 & -0.00093 & 0.00019 & -0.00018 \\
S07 & 0.00183 & -0.00183 & 0.00092 & -0.00091 & 0.00019 & -0.00018 \\
S08 & -0.00053 & 0.00055 & -0.00026 & 0.00028 & -0.00005 & 0.00006 \\
S09 & 0.00079 & -0.00078 & 0.00040 & -0.00039 & 0.00008 & -0.00007 \\
S10 & 0.00037 & -0.00035 & 0.00019 & -0.00018 & 0.00004 & -0.00003 \\
S11 & 0.00000 & 0.00000 & 0.00000 & 0.00000 & 0.00000 & 0.00000 \\
Transmission & 0.00128 & -0.00214 & 0.00043 & -0.00128 & -0.00026 & -0.00060 \\
Nuclear & -0.14769 & 0.14679 & -0.07408 & 0.07316 & -0.01518 & 0.01428 \\
Thermal & 0.07856 & -0.07939 & 0.03908 & -0.03991 & 0.00748 & -0.00831 \\
Hydro & 0.05535 & -0.05688 & 0.02727 & -0.02880 & 0.00483 & -0.00636 \\
Renewable & -1.11607 & 1.12422 & -0.55599 & 0.56415 & -0.10739 & 0.11555 \\
\hline
\end{tabular}


Table 9 Additional scenario for scenario 2

\begin{tabular}{lcccc}
\hline & Nuclear & Thermal & Hydro & Renewable \\
\hline Nuclear & -1.00 & 1.25 & 1.25 & -5.00 \\
Thermal & 1.25 & -1.00 & 1.25 & 5.00 \\
Hydro & 1.25 & 1.25 & -1.00 & -5.00 \\
Renewable & -5.00 & 5.00 & -5.00 & -1.00 \\
\hline
\end{tabular}

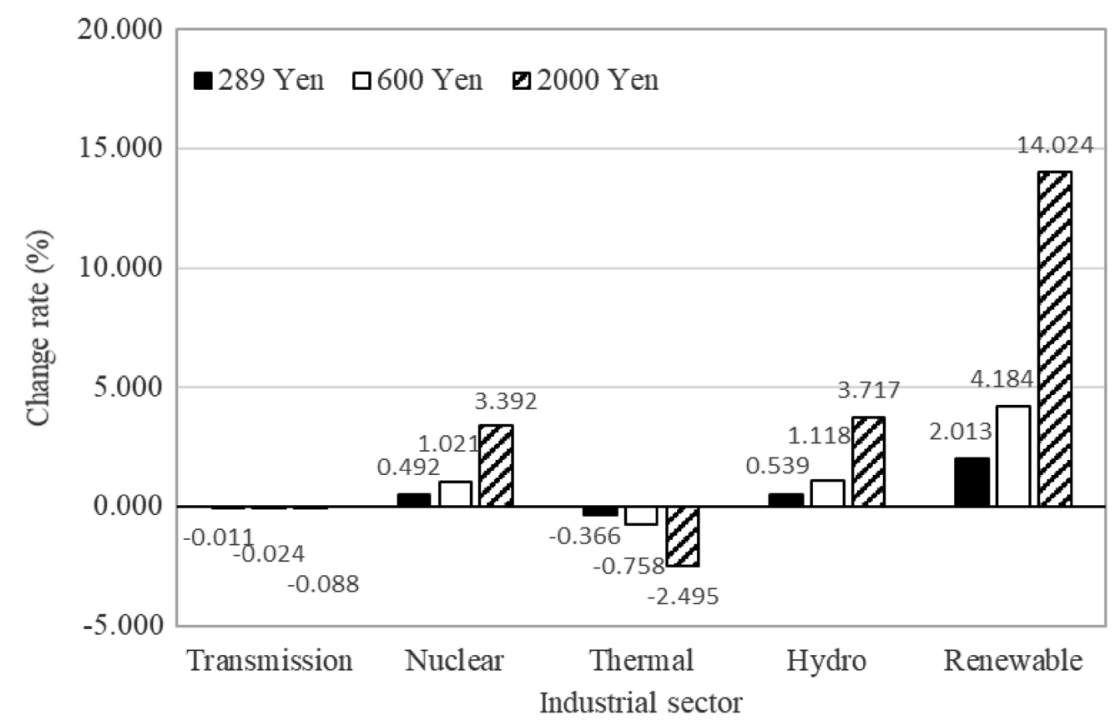

Fig. 6 The result of simulation of additional scenario

results show that the power switch from thermal power to renewable energy becomes smaller and substitution of nuclear and hydro for thermal power generation are slightly bigger than the original results. These results are attributed to the enhanced elasticity of substitution between the power sources.

Received: 27 February 2019 Accepted: 14 June 2019

Published online: 20 June 2019

\section{References}

Aydin L, Acar M (2010) Economic and environmental implications of Turkish accession to the European Union: a CGE analysis. Energy Policy 38:7031-7040

Barbe AJ (2014) A computable general equilibrium model of energy taxation with endogenous resource supply and flexible substitution. On the website (Accessed on 21 Aug 2018). Houston, Rice University. https://www.aeaweb.org/ conference/2014/retrieve.php?pdfid=164

Benavente JMG (2016) Impact of a carbon tax on the Chilean economy: a computable general equilibrium analysis. Energy Economics 57:106-127

Cabinet of Japan, "SNA Input-Output table." On the website (in Japanese) Accessed on 18 Feb 2019. https://www.esri.cao. go.jp/jp/sna/data/data_list/sangyou/files/files_sangyou.html

Danno M, Nemoto J, Yamaguchi T (2013) A simulation analysis of the feed-in tariff for residential solar electricity (in Japanese). Keizai Kagaku (Graduate school of Economics, Nagoya University), vol 61(1), pp 19-33. On the website (Accessed on 21 Nov 2018). https://nagoya.repo.nii.ac.jp/?action=pages_view_main\&active_action=repository _view_main_item_detail\&item_id=16248\&item_no=1\&page_id=28\&block_id=27 
Greenhouse Gas Inventory Office of Japan (GIO) Center for Global Environmental Research (CGER), and National Institute for Environmental Studies (NIES) (2018). "National greenhouse gas inventory report of Japan." Ministry of the Environment, Japan, pp 2-3, 2-12. On the website (Accessed on 27 Nov 2018). http://www-gio.nies.go.jp/aboutghg/ nir/2018/NIR-JPN-2018-v4.1_web.pdf

Guo Z, Zhang X, Zheng Y, Rao R (2014) Exploring the impacts of a carbon tax on the Chinese economy using a CGE model with a detailed disaggregation of energy sectors. Energy Econ 45:452-462

He YX, Zhang SL, Yang LY, Wang YJ, Wang J (2010) Economic analysis of coal price-electricity price adjustment in China based on the CGE model. Energy Policy 38:6629-6637

Hwang WS, Lee JD (2015) A CGE analysis for quantitative evaluation of electricity market changes. Energy Policy 83:69-81 Institute for Economic Analysis of Next-generation Science and Technology. Input-Output table for analysis of next-generation energy system: extended renewable energy sectors for 2005. Waseda University. On the website (Accessed on 27 Nov 2018). http://www.f.waseda.jp/washizu/table.html

Jorgenson DW, Yun KY (2001) Lifting the burden: Tax reform, the cost of capital and U.S. economic growth, vol 3. MIT Press, Cambridge

Li Y, Su B (2017) The impacts of carbon pricing on coastal megacities: a CGE analysis of Singapore. J Clean Prod 165:1239-1248

Ministry of Environment of Japan. "Comprehensive environmental countermeasures" (in Japanese). On the website (Accessed on 07 Feb 2019). https://www.env.go.jp/policy/tax/about.html

Peters JC (2016a) The GTAP-Power data base: disaggregating the electricity sector in the GTAP data base. J Glob Econ Anal 1(1):209-250

Peters JC (2016b) GTAP-E-Power: an electricity-detailed economy-wide model. J Glob Econ Anal 1(2):156-187

Tang L, Shi J, Yu L, Bao Q (2017) Economic and environmental influences of coal resource tax in China: a dynamic computable general equilibrium approach. Resour Conserv Recycl 117:34-44

The Mainichi Newspaper (2018.10.4) Kyushu Electric considers cutting off renewable energy feed-ins due to oversupply (Accessed on Dec 2018). (Available at https://mainichi.jp/english/articles/20181004/p2a/00m/0na/031000c)

Wilcoxen P (1988) The effects of environmental regulation and energy prices on U.S. economic performance. Ph.D. Dissertation. Harvard University, Cambridge

Wissema W, Dellink R (2007) AGE analysis of the impact of a carbon energy tax on the Irish economy. Ecol Econ 61:671-683

Yun T, Cho G, Kim J (2016) Analyzing economic effects with energy mix changes: a hybrid CGE model approach. Sustainability 8:1048. https://doi.org/10.3390/su8101048

Zhang X, Qi T, Ou X, Zhang X (2017) The role of multi-region integrated emissions trading scheme: a computable general equilibrium analysis. Appl Energy 185:1860-1868

\section{Publisher's Note}

Springer Nature remains neutral with regard to jurisdictional claims in published maps and institutional affiliations.

\section{Submit your manuscript to a SpringerOpen ${ }^{\circ}$ journal and benefit from:}

- Convenient online submission

- Rigorous peer review

- Open access: articles freely available online

- High visibility within the field

Retaining the copyright to your article

Submit your next manuscript at $\gg$ springeropen.com 